\title{
Influence of Background Knowledge and Language Proficiency on Comprehension of Domain-specific Texts by University Students
}

\begin{abstract}
This paper presents the results of a quantitative study that explores two factors contributing to reading comprehension of domain specific texts, namely, the level of language proficiency and background knowledge. Overall, 32 students participated in the study by taking two custom-designed reading comprehension tests. The test scores were further analyzed using SPSS statistical software. The results of statistical tests revealed the differences between study groups as well as the effects of compensation. More precisely, the most proficient group scored higher on almost all tests and completed the tests more quickly than the remaining groups. The statistical tools used to test the data showed that there are significant differences between all the groups in their performance on Proficiency Level Test and in timing. Hence our hypothesis concerning the influence of background knowledge and language proficiency on reading comprehension of domain-specific texts has been confirmed. Finally, the paper discusses limitations of the study as well as implications for EFL teaching.
\end{abstract}

Keywords: reading comprehension, background knowledge, language proficiency, domainspecific texts

\section{Introduction}

Text comprehension is a complex phenomenon. Each person has a unique experience as he or she is brought up in various social communities, learns about many traditions related to his or her family, visits places and encounters different people. What is more, young students learn about specific domains of 
knowledge, such as physics, music, or tourism. All these factors, and many more, shape their personality and have an influence on their worldview. Due to them, every person understands the received messages differently. The influence of experience and knowledge on the students' learning process has become a matter of discussion for different researchers. It has been also an intriguing issue for linguists interested in the processes of reading. They have conducted many studies concerning the influence of one's background knowledge on comprehension of different texts types (Carrel, 1983; Erten \& Razi, 2009; Joag-Dev \& Steffensen, 1995; Keshavarz \& Atai, 2007; Ridgway 1997; Yin, 1985). The general purpose of these studies was to check whether background knowledge can affect reading comprehension and, if so, how strong this influence can be.

This research ${ }^{1}$ focuses on the problem of background knowledge and its effects on one's reading comprehension. I observed that despite the high level of proficiency, some learners may face problems while reading a text on a specific subject matter. Very often, the terminology of some professions is opaque and not available to a layperson, hence the mere linguistic knowledge may not be enough to fully comprehend a text. Nevertheless, due to the high level of proficiency, some students of a foreign language may activate other factors in order to compensate for the lack of background knowledge.

\section{Reading, Reading Comprehension, and Background Knowledge}

Reading is a very important activity in people's lives. People read for different purposes - searching for information, entertainment, or learning, among others. However, the readers usually do not wonder what exactly reading is and what kind of processes are involved in this complex activity. Grabe and Stoller (2002, p. 9) claim that "reading is the ability to draw meaning from the printed page and interpret this information appropriately." Moreover, Urquhart and Weir $(1998$, p. 37) state that reading "largely takes place in the mind." At this point, it may be assumed that reading is not only the process of producing sounds corresponding to the signs printed on paper, but it also involves many mental processes that are activated while reading. According to Gough, Hoover, and Peterson (1996, p. 3),

${ }_{1}$ This research is a part of my MA thesis conducted under the supervision of Prof. Liliana Piasecka at the University of Opole in 2014. 
[a] child who cannot decode cannot read; a child who cannot comprehend cannot read either. Literacy_-reading ability — can be found only in the presence of both decoding and comprehension. Both skills are necessary; neither is sufficient.

Such a point of view shows that the reading ability is inevitably connected with the comprehension. In other words, reading any discourse without understanding it would be pointless.

Comprehension of a text is an essential issue in the process of decoding a printed text. It may be seen as a process of assigning meaning to any discourse and "getting information from written text" (Urquhart \& Weir, 1998, p. 85). Sousa (2014, p. 101) lists five actions that a reader engages in order to comprehend a text, and these are "identifying words by using knowledge outside the text, accessing word meaning in context, recognizing grammatical structures, drawing inferences, and self-monitoring." Hence, it can be assumed that comprehension of a text is a complex phenomenon, and the different interactive processes require a reader to become an active reader responsible for the meaning that he or she derives from a text.

Comprehension involves a number of factors, and those are predicting the content of a text, confirming predictions with the content and, eventually, changing or complementing predictions (Goodman, 1971). The predictions are connected with readers' knowledge about the world and a subject matter. On the basis of Goodman's view, Coady (1979) proposed a basic model of English as a second language (ESL) reader. He states that during the process of reading and comprehending the text, ESL reader uses his or her conceptual abilities, which means a reader's intellectual capacity, processing strategies, including "e.g. grapheme-morpho-phoneme correspondences, syllable-morpheme information (deep and surface), lexical meaning and contextual meaning" (Carrel \& Eisterhold, 1987, p. 219) as well as background knowledge. Each of these components integrate with others resulting in comprehension. Moreover, as Piasecka (2008) notices our understanding of a written text is bound to the frameworks of our culture and society. It is easier for a reader to comprehend a text that is closer to his or her cultural context. This issue is also connected with the reader's background knowledge. As Clarke and Silberstein (1977, p. 137) claim, "skill in reading depends on the efficient interaction between linguistic knowledge and knowledge of the world." Hence, in order to establish a working definition of reading, it may be concluded that every act of reading, or decoding a written text, should be strictly connected with comprehension that requires from a reader an active participation in a reading process, using particular information stored in his or her mind--in other words, his or her background knowledge. 
Looking at factors that affect reading, Bernhardt (1996, p. 93) comments that "knowledge can be defined as that information held by the writer and assumed to be known to the reader." Many researchers claim that the knowledge which a reader brings to the reading activity is crucial in understanding any discourse. Saville-Troike (2006) assumes that the progress in reading depends on how much background knowledge a reader has when he or she starts reading.

According to Bernhardt (1996), there are three types of knowledge, namely, local-level knowledge operating among a specific group of people, culturespecific knowledge that includes familiarity with rituals or history of a given group, and domain-specific knowledge, the latter being the focus of this study. Throughout the school education, one learns specific domains of knowledge such as history, music, physics or math. However, this kind of knowledge does not have to be gathered by institutional learning only.

Carrell and Eisterhold (1987, p. 220) maintain that the text alone does not carry any meaning in itself; it is rather one's prior knowledge which directs the reader's attention to the meaning of the text. They also state that the reader's "previously acquired knowledge structures are called schemata," which means that when reading a text, readers relate its content to their already existing schemata which may not be literally and explicitly written down. Thus, many readers may comprehend the same text in the different ways, as everything depends on their prior knowledge connected with a text's subject matter.

\section{Research Review on the Readers' Prior Knowledge}

The influence of background knowledge on text comprehension has been already addressed by researchers (Joag-Dev \& Steffensen, 1995; Yin, 1985; Ridgway, 1997; Keshavarz \& Atai, 2007; Erten \& Razi, 2009). For example, Steffensen and Joag-Dev (1995) explored why proficient language learners have difficulties in understanding texts in a foreign language. The main focus of their research was schema theory and the functions of schemata in text comprehension. The authors formulated some hypotheses, one of which was that the readers would recall more information from the text in their native language than in a foreign language. Moreover, it was believed that students will make more culture related connotations, even if they are not literally stated in the text. What is more, it was predicted that the participants would need more time to read in the foreign language than in their native one.

The results showed that the cultural knowledge significantly affects text comprehension as the readers make more or less appropriate inferences while trying to derive meaning from the text. If the readers lack specific kind of 
background knowledge, they will attempt to use the knowledge they have already gathered and adopt it into a text.

The study conducted by Yin (1985) concentrates on whether readers' prior knowledge influences their comprehension of domain-specific texts. The author focused specifically on background knowledge, considering it as a factor which can significantly influence reconstructing the meaning of a text. Hence, she sees prior knowledge as the sum of knowledge about language and other kinds of relevant knowledge that a reader has already accumulated. Yin (1985) maintains that one needs prior knowledge in order to correctly interpret a written message.

The results of the experiment conducted by Yin (1985) confirmed the assumption that readers' prior knowledge connected with a content of a text and the linguistic proficiency play an important role in understanding domainspecific texts. The experiment also revealed that the absence of one factor, for example, prior knowledge or linguistic proficiency, can be compensated by the activation of the other. Hence, the author implies that the second language teachers should focus more on the process of reading than on the sole product of it. They should make students aware of the factors influencing reading, and they should develop troubleshooting or problem-solving strategies among students by using all kind of knowledge and skills that the students have already acquired.

Keshavarz and Atai (2007) investigated whether the content schemata have a significant effect on text comprehension and attempted to verify whether it interacts with the readers' proficiency and text simplification. The results proved that content schemata affect comprehension stronger than simplification.

Erten and Razi (2009) focused on the background knowledge connected with the readers' culture as they aimed to provide evidence that cultural familiarity with a short story exerts influence on reading comprehension. The said researchers found that the readers comprehend more and are more motivated while reading a text connected with their experience and culture.

The objective of Ridgway's study (1997) was to verify whether effects of schemata would occur only between two linguistic thresholds. The results partially confirmed the author's assumption, as they revealed that the students always use background knowledge but its effect is not always seen.

In a similar vein, the main goal of the study presented in this paper is to verify whether the students' background knowledge and linguistic proficiency influence their understanding of a text on a specific subject matter. This study provides a complementary perspective on the relationship between background knowledge and reading comprehension as it does not take into consideration the cultural background of the participant, but it takes into account an influence of participants' linguistic proficiency. The methodology and research material used in this study are described in the following section. 


\section{Research Material and Methodology}

\section{Aim of the Study and Research Questions}

As it was previously mentioned, background knowledge is a significant factor influencing readers' text comprehension. Thus, the goal of this study is to check how students of different study programmes (law, computer science, English philology) would perform on texts devoted to various subject matters, and whether the prior knowledge has a significant impact on text comprehension. What is more, apart from background knowledge also the readers' level of proficiency affects the process of text comprehension. Hence, another goal of this study was to check whether the readers who are more proficient in language would perform similarly or better on the texts that are not connected with their interest or study programme than the students who are less proficient, but who read the texts based on a subject matter familiar to them.

Hence, the hypothesis put forward in this study implies that the participants will perform better on the texts based on the topics familiar to them. What is more, it is also assumed that the participants' higher level of proficiency will compensate for their lack of domain-specific knowledge. As a result, this study aims to provide answers to the following research questions:

1. Does background knowledge influence comprehension of domain specific texts?

2. Does the higher level of linguistic proficiency compensate for the lack of domain-specific knowledge?

\section{Participants}

All in all, 40 participants took part in the study, however, since eight students did not take the second test they were not taken into consideration in overall findings. The participants were the students of law, computer science, and English philology at the University of Opole. The first group of participants were the students of law (LFG) who were in their second year of their study, aged between 20-23 years, with the mean-age of 20.8. Generally, 20 participants from this group took part in the study, but only 12 of them took both tests; there were seven female and five male participants. On average, they had been learning English for 12 years, ranging from six to 18 years. The second group were students of computer science (CSG), who were also in their second year of study. The mean-age was 21.9, ranging from 20 to 23 years, and they had been learning English for ten years at the time, ranging from 15 years to three years. There were 11 males in the group. The third group were students of 
English philology (EPG) in the fourth year of their study, aged between 22-24 years; their average age was 22.8. There were nine participants in the group, that is, one male and eight females. They had been learning English for 13.9 years on average, ranging from 12 to 17 years.

\section{Materials}

The data subjected to the analysis included the results of two tests. The first test consisted of two parts, namely, personal questionnaire and a test assessing the participants' level of linguistic proficiency. The tasks varied in the level of difficulty. The maximum score on the proficiency level test was 49 points.

The second test comprised three texts arranged randomly. One text was connected with the domain of law and dealt with the history of Common Law. The other text was devoted to Computer Science and its subject was a review of a PC. There was also a neutral text based on the topic not connected with the aforementioned study programmes; it dealt with the beginnings of religion in ancient Scandinavia. The maximum score for text from the legal domain text was nine points, for the text devoted to Computer Science-nine points, and for the neutral text it was five points. Hence the total number of points was 23 .

\section{Procedure and Stages of the Study}

As it was mentioned earlier in the paper, there were three groups and each participant had to take two tests. All the participants were asked to sign the tests, as the results of the first test were then related to the results of the second one. The first group that took the test was LFG. They had to fill in personal questionnaire and deal with tasks for determining the level of linguistic proficiency. Two weeks later, during the second meeting, the students were given three texts arranged randomly, thus each participant had a different order of the texts. Meanwhile, the CSG took the first test, and after two weeks, the second test was administered to this group. The last was EPG, who were administered the first test in June, and the second one in October, which was due to the vacation period. The SPSS program was used for statistical analysis of the test results. 


\section{Results}

The results of the tests are presented in the form of figures. The first tool used in the study was the linguistic proficiency level test. The results of the test are provided in Figures 1, 2, where minimum and maximum scores, means, as well as standard deviation are presented for all the three groups. The highest standard deviation (SD) in score was recorded for EPG (5.38) and in time-CSG (8.96), which means that these groups are more differentiated. The lowest SD in score (4.52) is found in CSG, and in time (3.35) in EPG, which means that these two groups are more homogenous. It can be observed that the EPG not only achieved the highest score on the proficiency level test, but also completed the test the fastest of all. What is more, the CSG group that scored the lowest needed more time than the remaining groups to complete the task.

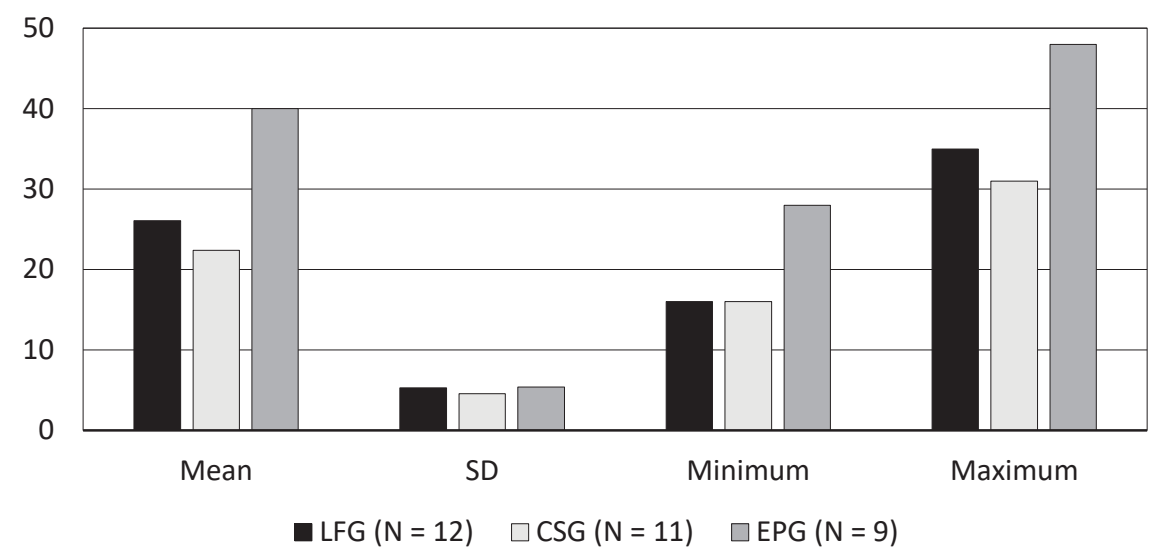

Figure 1. The results of the proficiency level test (maximum score 49 points).

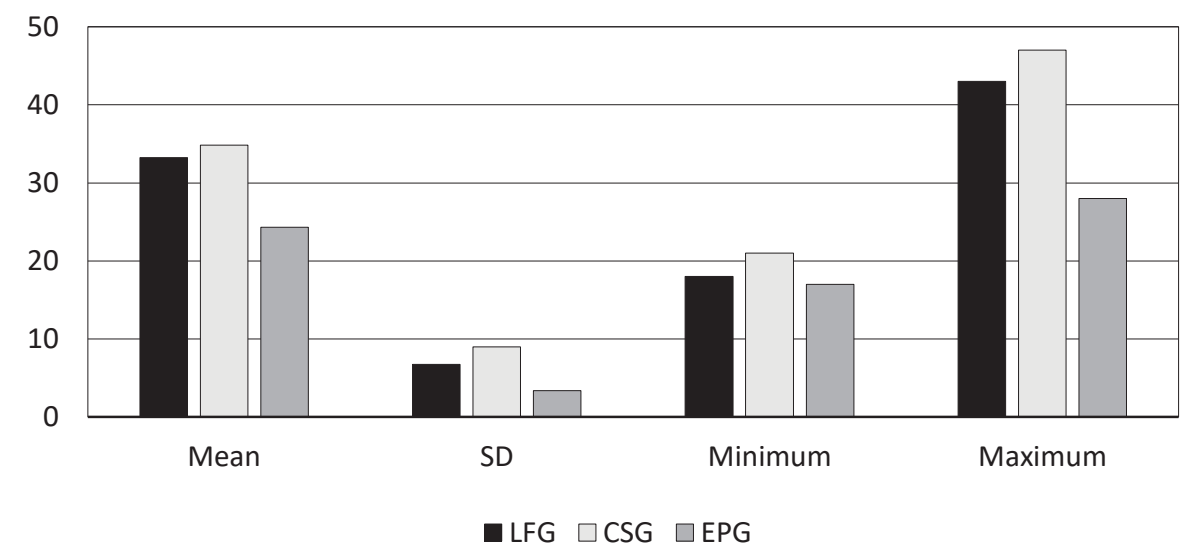

Figure 2. Time of performance of the proficiency level test. 
Figures 3, 4, 5 present the results of the second test. According to the data, the lowest mean for all three texts were recorded in LFG, although they scored better on the proficiency level test than CSG. An interesting finding is that LFG has the lowest score on the text connected with the subject matter of their studies, namely, the text about the history of common law. This group scored better on the text which was on the topic unfamiliar to them, that is a computer science text. It is presumed that there are at least two factors which influenced the LFG students' performance and these are their approach to test two, which was rather unconcerned, and the omnipresence of various electronic and computer devices in our day-to-day life. According to our assumptions, the CSG performed best of all the three groups on the computer science text. EPG not only has the highest score, but also performed best on the proficiency

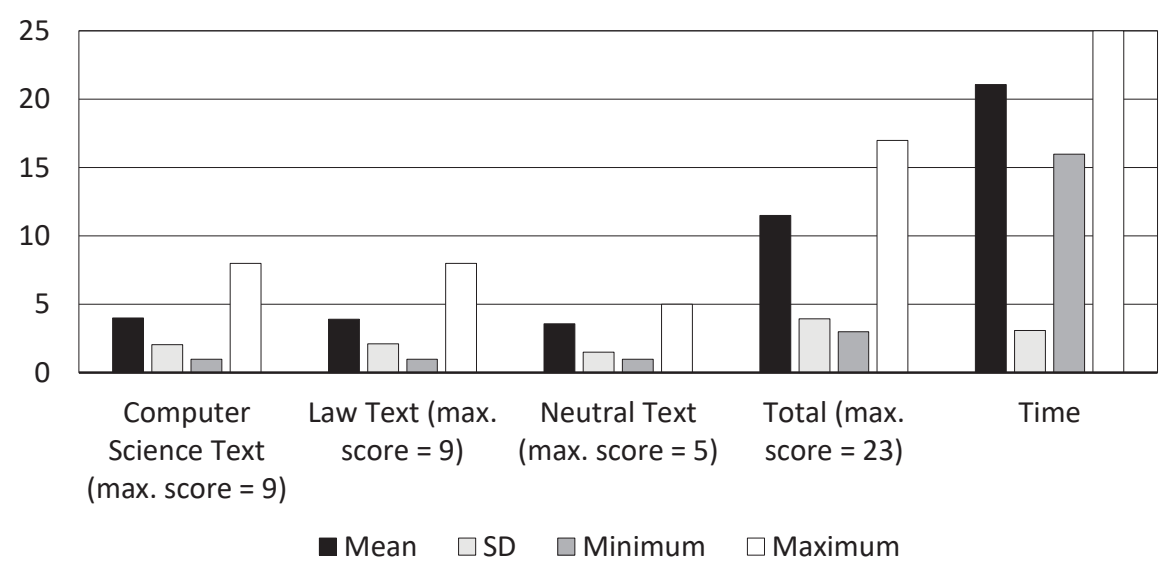

Figure 3. The results of test two-LFG.

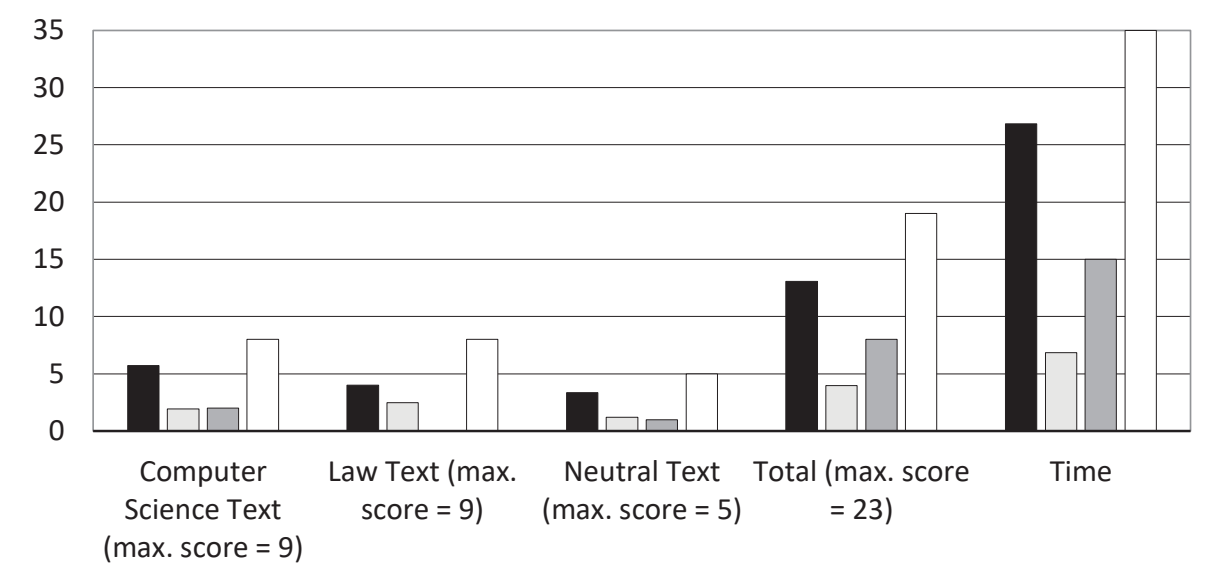

Figure 4. The results of test two-CSG. 


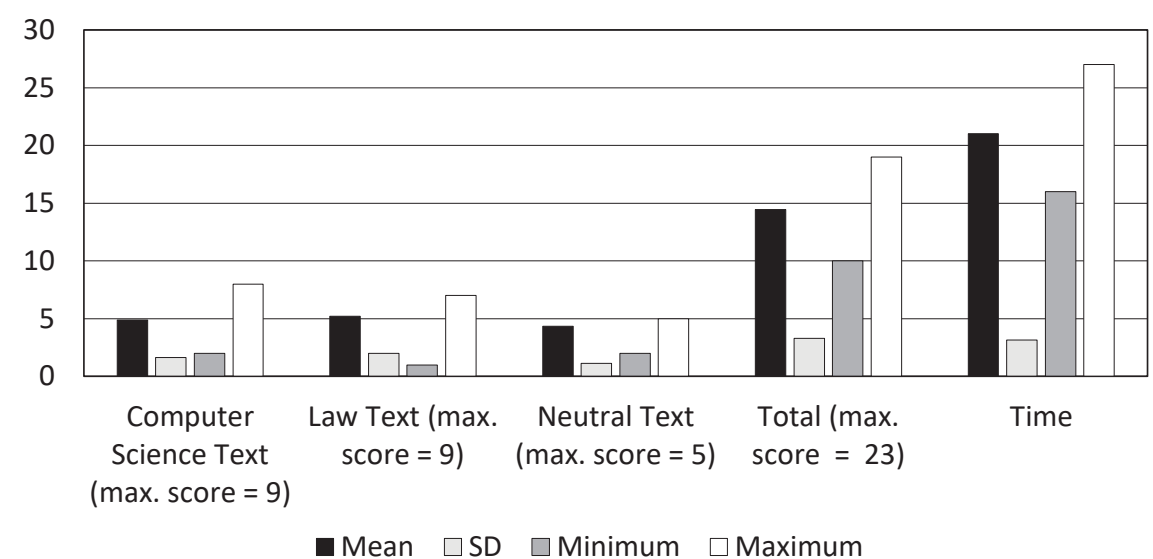

Figure 5. The results of test two-EPG.

level test. This group appears to be the most homogenous since the standard deviation in this group is 3.28 .

What is more, the non-parametric Kruskal-Wallis test for ranked data was used to verify whether there are statistically significant differences between the groups under scrutiny. Figure 6 presents the results of the Kruskal-Wallis test. The non-parametric Kruskal-Wallis test shows that there are almost no significant differences between the groups. Hence, a relation between the students from different study programmes and the reading comprehension of domain-specific test cannot be assumed. The test presents only two significant differences, the first one in Proficiency Level Test $(p=0,00)$, and the second one in Time 1 (time of performance of Proficiency Level Test) $(p=0,005)$.

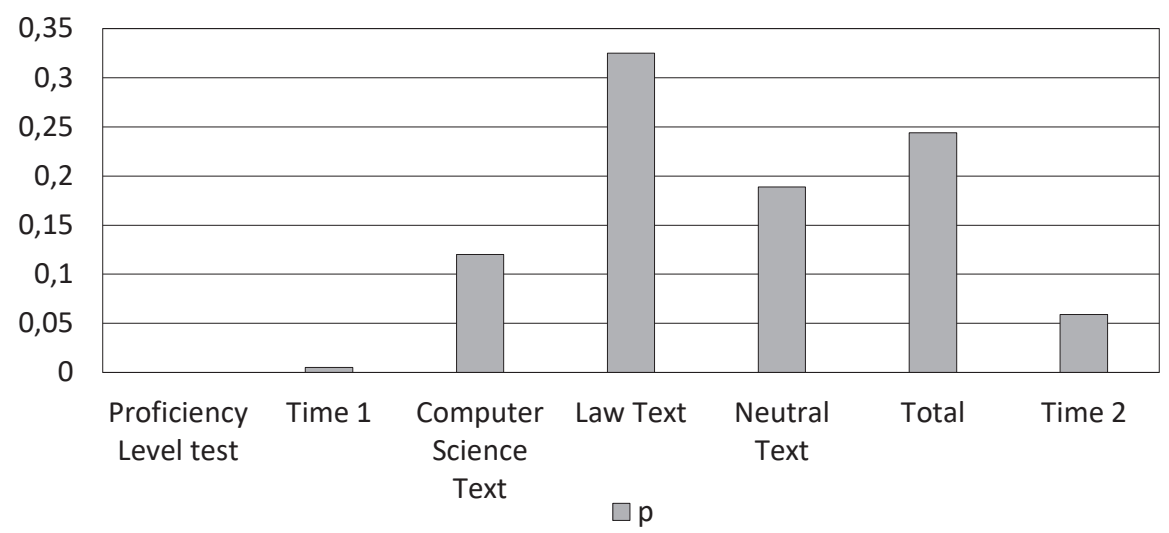

Figure 6. The Kruskal-Wallis test.

Furthermore, I checked the correlation between the results from the proficiency level text and the scores from test two. The results are presented in 
Figure 7 and show that the correlation between the level of proficiency and comprehension of domain-specific texts holds three cases. The level of proficiency of the students from EPG correlates positively with comprehension of the neutral text $(p=0.02$, correlation $=0.77)$. What is more, the total score from all three texts also shows a positive correlation with EPG level of proficiency $(p=0.01$, correlation $=0.78)$. Moreover, the scores from all three groups from the proficiency level test correlate positively with the scores from the neutral text $(p=0.03$, correlation $=0.38)$. Nevertheless, in these three cases, the results present a moderate correlation between the variables, hence a cause and effect relation between the level of proficiency and the reading comprehension cannot be indicated. LFG's and CSG's level of proficiency does not correlate positively with text comprehension $(p>0.05)$.

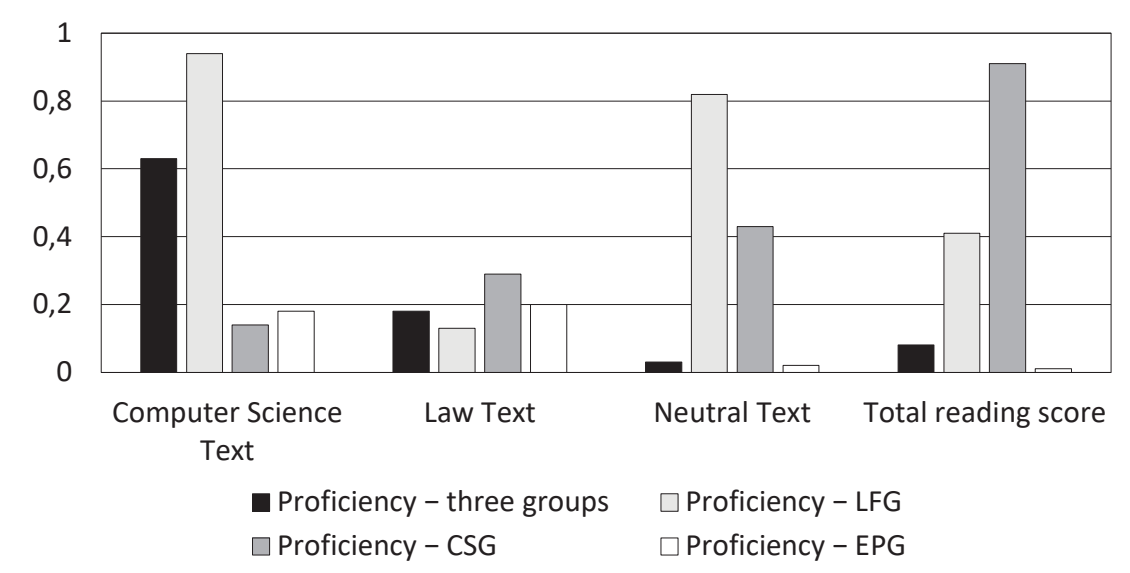

Figure 7. The correlations.

\section{Discussion}

The data collected during the study proves that there is almost no statistically significant influence of background knowledge on the comprehension of texts devoted to a subject matter familiar to readers (Figure 6, 7). There was only one case where the prior knowledge influenced comprehension, and it occurred in the group of students of computer science, who achieved the highest score on the computer science text, however, the result does not prove to be statistically significant. In contrast, students of law scored the lowest on the text on the subject matter that was supposed to be familiar to them. Although the results show that there are differences in the groups' performance on texts with different subject matters (Figures 3, 4, and 5), the tools used to process the data show that these differences are not statistically significant. 
The results from the correlation test (Figure 7) show that there is a correlation between the students' level of proficiency and text comprehension. The correlation holds in the case of English philology students, who achieved the highest score on the proficiency level test, and their results moderately correlate with the scores from the neutral text and their total score from comprehension test. It is also seen that the English philology students achieved the highest scores on almost all texts. The exception here is the group of computer science students, who scored better on a computer science text.

The two hypotheses presented in this study state that the participants will perform better on the texts describing the topics familiar to them, and that the participant's higher level of linguistic proficiency will compensate for the lack of domain-specific knowledge. In the light of the reported results, both hypotheses can be confirmed only partially. The students of computer science performed better on the text familiar to them, nevertheless, the students of law scored the lowest on the text connected with their studies. This group performed better on the computer science text. Similar findings were also reported in the study conducted by Ridgway (1997), who assumed that some concepts are more universally available, hence even a layperson can access information on them, for example in mass media. Nowadays, people are surrounded by different kinds of electronic devices, thus the wording connected with this subject matter could be familiar not only for the computer science students. What is more, the vocabulary used in the domain of law is more difficult and opaque, notably for a layperson, and that is why it may cause more problems while reading and comprehending the text. In addition, legal texts usually contain many terms of Latin origin, which can further hinder text processing and understanding by readers. However, the students of law admitted in the questionnaire that they know Latin language.

Finally, it was found that the group of English philology students proved to be more proficient linguistically, and they scored the highest on almost all texts. What is more, the Kruskal-Wallis test shows significant differences between the groups in the Proficiency Level Test (Figure 6) and the total score of test two proves to be statistically significant and correlates positively with the English philology students' level of proficiency (Figure 7). Saville-Troike (2006) states that advanced reading is more demanding as it includes the knowledge of both basic and domain-specific vocabulary. The sentence structure of domain-specific texts is also more complex. Thus, understanding specialized texts "requires extensive exposure to written text because vocabulary, grammar and discourse structures differ in the kind of language used for academic versus interpersonal purposes" (Saville-Troike, 2006, p. 159). This assumption offers an explanation to the highest score of the English philology students. Not only are they more proficient in language skills, but also they are more exposed to various types of academic and subject-specific texts written in English throughout their en- 
tire study programme. Moreover, the timing from both tests also appears to be significant as the students from the English philology group needed less time to complete the tests, as compared with the remaining groups. The KruskalWallis presents statistically significant differences between the groups in time of performance of the first test (Figure 6). However, their automaticity in reading and processing information was conscious so they completed the tasks accurately. In Yin's study (1985), it appeared that the proficiency in language can compensate for the lack of background knowledge, which means that the results reported in this study confirm Yin's findings. Nevertheless, one has to admit that 180 participants took part in the study conducted by Yin (1985), while only 32 students were participants in the presented study. Hence, the small number of students can also be the factor that influenced the results, which should not be construed of as definitive. That is why it is important to further verify the results of this study by conducting it with a higher number of students. It may be expected, among others, that the level of linguistic proficiency will have a greater influence text comprehension.

\section{Conclusions}

As the role of background knowledge and linguistic competence in reading comprehension is rather multifaceted, I realise that this study has certain limitations. As mentioned earlier, the first limitation is the number of participants. The total number of students in my study was 32 whilst in other studies there were, for example, 69 students (Ridgway, 1997) or even 180 (Yin, 1985). It can be assumed that with the greater number of participants, the influence of both prior knowledge and language proficiency might prove to be stronger.

Secondly, the omnipresence of technology and different kinds of electronic devices might have also affected the results of the study, as the students might be well-familiar with the vocabulary connected with the subject of computer science. It can be assumed that the participants could have already gathered the background knowledge connected with computers, even if they do not study computer science. On the other hand, there are also some domains where wording is more opaque and difficult for non-specialists (e.g., law). Obviously enough, since I did not assess the participants' domain-specific knowledge, this issue is a mere theoretical speculation.

Another factor that could have played an important role in the study is the students' motivation and attitude toward the research. According to Norris-Holt (2001, para. 20) "motivation is an important variable when examining successful second language acquisition." It was noticed that one group's approach 
was rather indifferent (LFG). Such an approach can affect the final results, as nonchalance does not facilitate text comprehension.

Finally, the format of the test could also have influenced the results. On test two the participants were asked to fill in the gaps. It can be speculated that if the students were administered the recall test, which requires producing their own answers, the scores would be different.

\section{Implications for ESL Classroom Teaching}

As the study proves, background knowledge facilitates comprehension of written discourse. Carrell and Eisterhold (1987) suggest that while administering reading exercises to students, teachers should activate appropriate schemata that the students already have and use in order to help them understand a text. This can be achieved by providing the students with cues in the text. In that case, graphic images may be very helpful as the students may easily associate them with the written language and information conveyed in the text.

Although the students may be given the cues, they may still not comprehend a text because they may lack those schemata. Thus, the teachers should provide their students with the background knowledge before reading tasks. As Richgels (1982) notices, it is much easier for the students to understand or elicit meaning from a text which describes a topic familiar to them. It is important to adequately prepare the students before assessing their knowledge of an unfamiliar subject. The different kinds of pre-tasks that aim at providing the students with background knowledge are useful as the starting point of reading. Moreover, according to Keshavarz and Atai (2007), the teachers should not teach new linguistic items (words, expressions or phraseologies) on the texts which concern unfamiliar topics. This approach might be too challenging for the students as they may not find any cues in the text.

It is also important to develop the process of active reading in the students. This means that the students should actively participate in reading exercises by noticing textual cues, interpreting them correctly, making inferences and using every kind of knowledge that is available to them. The students should also get to know how to use language resources, for example monolingual and bilingual dictionaries and, if possible, language corpora. As Yin (1985) notices, the teachers should focus on the process of learning a language, not only on its product. Teaching students to become more conscious and independent in their process of acquiring a target language is crucial as it leads to success in language learning.

Nevertheless, students may have appropriate knowledge, but they might find it difficult to activate it due to a low level of language proficiency. Teachers should therefore encourage the students both to develop a rich vocabulary and to 
learn about language structures, as it leads to greater comprehension of a written text. The study proves that some of the reading problems may be caused by a lower level of linguistic proficiency. The students who lack background knowledge try to activate every source possible in order to facilitate reading. Hence, developing all language skills is a crucial factor in the process of reading and text comprehension.

\section{References}

Bernhardt, E. B. (1996). Reading development in a second language: Theoretical empirical, and classroom perspectives. Norwood, NJ: Alex Publishing Corporation.

Carrel, P. L. (1983). Some issues in studying the role of schemata, or background knowledge, in second language comprehension. Paper presented at the 17th Annual TESOL Convention, Toronto, Ontario, Canada, March 1983.

Clark, M. J., \& Silberstein, S. (1977). Toward a realization of psycholinguistic principles in the ESL reading class. Language Learning, 27(1), 135-154.

Coady, J. (1979). A psycholinguistic model of ESL reader. In R. Mackay, B. Barkman, \& R. R. Jordan (Eds.), Reading in a second language (pp. 5-12). Rowley, MA: Newbury House Publishers.

Erten, I. H., \& Razi, S. (2009). The effects of cultural familiarity on reading comprehension. Reading in a Foreign Language, 21(1), 60-77.

Goodman, K. (1971). Psycholinguistic universals in the reading process. In P. Pimskeur \& T. Quinn (Eds.), The psychology of second language learning (pp. 135-142). Cambridge: Cambridge University Press.

Gough, P. B., Hoover, W. A., \& Peterson, C. L. (1996). Some observations on the simple view of reading. In C. Cornoldi \& J. Oakhill (Eds.), Reading comprehension difficulties (pp. 1-13). Hillsdale, NJ: Erlbaum.

Grabe, W., \& Stoller, F. L. (2002). Teaching and researching reading. Edinburgh: Pearson Education.

Joag-Dev, Ch., \& Steffensen, M. S. (1995). Cultural knowledge and reading. In J. Ch. Alderson \& A. H. Urquhart (Eds.), Reading in a foreign language (pp. 48-64). New York: Longman.

Keshavarz, M. H., \& Atai, M. R. (2007). Content schema, linguistic simplification, and EFL readers' comprehension and recall. Reading in a Foreign Language, 19(1), 19-33.

Norris-Holt, J. (2001). Motivation as a contributing factor in second language acquisition. The Internet TESL Journal, 7(6). Retrieved from: http://iteslj.org/Articles/Norris-Motivation. html

Piasecka, L. (2008). Psycholinguistic and socio-cultural perspectives on native and foreign language reading. Opole: Wydawnictwo Uniwersytetu Opolskiego.

Richgels, D. J. (1982). Schema theory and representations of reading comprehension. The Journal of Education Research, 76(1), 54-62.

Ridgway, T. (1997). Thresholds of the background knowledge effect in foreign language reading. Reading in a Foreign Language, 11(1), 151-168.

Saville-Troike, M. (2006). Introducing Second Language Acquisition. New York: Cambridge University Press. 
Singhal, M. (1998). A comparison of L1 and L2 reading: Cultural differences and schemata. The Internet TESL Journal, 4(10). Retrieved from: http://iteslj.org/Articles/Singhal-ReadingL1L2. html

Sousa, D. A. (2014). How the brain learns to read. 2nd ed. New York: Sage Publications.

Urquhart, A. H., \& Weir, C. J. (1998). Reading in a second language: Process, product and practice. New York: Longman.

Yin, K. M. (1985). The role of prior knowledge in reading comprehension. Reading in a Foreign Language, 3(1), 375-380.

Justyna Kendik-Gut

\section{Zum Einfluss des Fachwissens und des Sprachniveaus der Studierenden auf das Verstehen von Fachtexten}

\section{Zusammenfassung}

Diese Studie befasst sich mit dem Einfluss des Fachwissens auf das Verstehen von fremdsprachigen Fachtexten. Darüber hinaus wird das Problem der allgemeinen Sprachkenntnisse aufgeworfen, zu untersuchen ist dabei, ob ein höheres Sprachniveau den Mangel am Fachwissen ausgleichen kann. An der Untersuchung nahmen 32 Studierende der Universität Oppeln teil - 12 Jurastudierende, 11 Informatikstudierende und 9 Studierende der Englischen Philologie. Die umfassende Analyse der Umfrageergebnisse ergab, dass das Fachwissen keinen statistisch signifikanten Einfluss auf das Textverstehen hat. Die Analyse der Zusammenhänge zwischen dem Sprachniveau und dem Textverstehen zeigte, dass ein höheres Sprachniveau nicht nur das bessere Textverstehen beeinflusst, sondern auch den Leseprozess beschleunigt. Einer der Faktoren, der zu Forschungseinschränkungen führen kann, ist die geringe Teilnehmerzahl. Es ist möglich, dass bei ihrer größeren Anzahl die Auswirkungen von Fachwissen und Sprachniveau höher sein könnten.

Schlüsselwörter: Lesefertigkeit, Hintergrundwissen, Sprachkenntnisse, fachspezifische Texte 